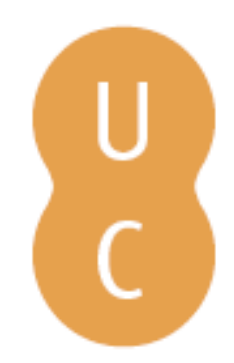

\title{
pommalina
}

\section{Metamorfoses com TICs}

Autor(es): Bernardes, Mário

Publicado por: Imprensa da Universidade de Coimbra

URL

persistente: URI:http://hdl.handle.net/10316.2/36998

DOI: $\quad$ DOI:http://dx.doi.org/10.14195/978-989-26-1045-0_27

Accessed : $\quad$ 26-Apr-2023 12:19:21

A navegação consulta e descarregamento dos títulos inseridos nas Bibliotecas Digitais UC Digitalis, UC Pombalina e UC Impactum, pressupõem a aceitação plena e sem reservas dos Termos e Condições de Uso destas Bibliotecas Digitais, disponíveis em https://digitalis.uc.pt/pt-pt/termos.

Conforme exposto nos referidos Termos e Condições de Uso, o descarregamento de títulos de acesso restrito requer uma licença válida de autorização devendo o utilizador aceder ao(s) documento(s) a partir de um endereço de IP da instituição detentora da supramencionada licença.

Ao utilizador é apenas permitido o descarregamento para uso pessoal, pelo que o emprego do(s) título(s) descarregado(s) para outro fim, designadamente comercial, carece de autorização do respetivo autor ou editor da obra.

Na medida em que todas as obras da UC Digitalis se encontram protegidas pelo Código do Direito de Autor e Direitos Conexos e demais legislação aplicável, toda a cópia, parcial ou total, deste documento, nos casos em que é legalmente admitida, deverá conter ou fazer-se acompanhar por este aviso.

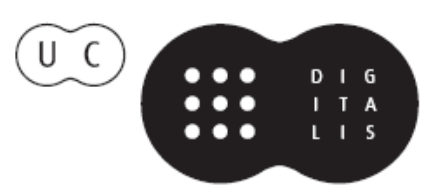



Tendo como pano de fundo as Comemorações dos seus 500 anos, a Biblioteca Geral da Universidade de Coimbra organizou um Congresso Internacional subordinado ao tema "A Biblioteca da Universidade: permanência e metamorfoses", que teve lugar nos dias 16, 17 e 18 de janeiro de 2014, no auditório da Reitoria da Universidade de Coimbra.

O objetivo maior desta reunião científica foi o de refletir sobre o presente e o futuro das bibliotecas que servem públicos universitários. Numa outra vertente, procurou chamar-se a atenção para a importância de que a Biblioteca se reveste, tendo em vista o progresso do conhecimento técnico e científico. Por último, o Congresso pretendeu instituir-se como oportunidade de reflexão prospetiva e como lugar de encontro entre as sensibilidades de todos os que trabalham profissionalmente com livros e com outros suportes de natureza bibliográfica.

Nesse sentido, foram apresentadas Conferências, Mesas Redondas e sessões de Testemunhos em torno de temas como o valor das bibliotecas universitárias, a biblioteca universitária em contexto; as mudanças e os desafios; a biblioteca universitária e a sociedade da informação e conhecimento; o impacto do acesso aberto na comunidade científica, e as bibliotecas digitais. 
MÁRIO BERNARDES

Universidade de Coimbra

\section{METAMORFOSESCOMTICS}

O convite que me foi formulado pelo Diretor da Biblioteca Geral da Universidade de Coimbra, para presidir à conferência "Regresso ao Futuro, 500 Anos Depois", integrada no Congresso Internacional "A Biblioteca da Universidade: permanência e metamorfoses", revestiu-se de um significado especial por diversos motivos. Para além do privilégio de me permitir participar nas comemorações dos 500 Anos da Biblioteca da Universidade de Coimbra, este convite proporcionou também uma oportunidade para reflexão não só sobre as metamorfoses no contexto das tecnologias da informação e comunicação (TIC), que tive oportunidade de acompanhar nos últimos 30 anos na Biblioteca Geral da Universidade de Coimbra e do Serviço Integrado de Bibliotecas da UC (SIBUC), como também sobre as metamorfoses presentes e futuras que trazem novas perspetivas e expectativas dos serviços bibliotecnómicos e, ao mesmo tempo, colocam também enormes desafios. Assim, neste breve texto descrevo, de forma necessariamente resumida, as fases (ou metamorfoses) que, ao longo destes anos, identifiquei como mais relevantes para a Biblioteca Geral da UC (BGUC), designadamente a etapa inicial de aproximação às TIC e a consequente adoção de sistemas aplicacionais mais evoluídos, a implementação de repositórios digitais de acesso aberto e, finalmente a etapa mais atual, contemporânea da gestão de conteúdos digitais e dos livros eletrónicos.

No início dos anos oitenta registou-se a primeira grande metamorfose de adoção de TIC na BGUC com a utilização muito significativa do Porbase MiniMicro CDS/ISIS, uma aplicação desenvolvida pela UNESCO e adaptada pela Biblioteca Nacional. Sendo uma aplicação para compu- 
tadores pessoais com sistema de operação MS-DOS, não podia reunir as funcionalidades do que então se designava por um sistema integrado de gestão de bibliotecas (SIGB).

Contudo, o Porbase MiniMicro CDS/ISIS não era uma aplicação desenhada para dar resposta aos requisitos de bibliotecas com a dimensão da BGUC e das bibliotecas de instituições de ensino superior em geral, pelo que foi necessário avaliar alternativas. Com este objetivo, a Universidade de Coimbra e a IBM Portugal desenvolveram um protocolo para avaliar o sistema integrado de gestão de bibliotecas DOBIS LIBIS, desenvolvido pela Universidade de Lovaina, por forma a permitir a sua utilização nas bibliotecas do SIIB-Centro, um consórcio constituído pela Universidade da Beira Interior, bibliotecas municipais, institutos politécnicos e pela UC. Tendo-se registado diversas dificuldades técnicas de integração na rede da UC em resultado da tecnologia proprietária utilizada pelo DOBIS LIBIS, assim como dos elevados custos de exploração e dificuldade de adaptação às normas portuguesas de bibliotecas, o projeto foi terminado em 1994.

Após esta experiência a BGUC lançou um concurso público para aquisição de um novo sistema integrado de gestão de bibliotecas, em resultado do qual foi adquirido o SLS Libertas que, pela primeira vez, permitiu disponibilizar em rede o catálogo da maioria das bibliotecas da UC. O sistema era explorado sobre o sistema de operação VAX/VMS da Digital Equipment e oferecia uma interface de utilização baseada em caracteres, isto é, não gráfica. No entanto, este sistema já oferecia uma interface adicional simples para pesquisa bibliográfica orientada para a Web. O Libertas entrou em produção em 1997 e foi utilizado na UC durante cerca de dez anos.

No fim deste período, a necessidade de atualização tecnológica e o percurso da empresa responsável pelo desenvolvimento do Libertas levaram a BGUC a reavaliar as soluções disponíveis tendo sido lançado novo concurso público do qual resultou a adoção do Millennium, um produto com uma tecnologia mais evoluída, suportado por uma base de dados relacional, com uma interface gráfica em modelo cliente-servidor e com uma interface web para acesso público ao catálogo (Online Public Access 
Catalog, OPAC). O Millennium entrou em produção em 2007, permitiu reunir num único catálogo todas as bibliotecas da UC, sendo o sistema em utilização na UC na presente data.

Os sistemas integrados de gestão em exploração na generalidade das bibliotecas são orientados para a gestão de conteúdos físicos, como livros e periódicos em suporte de papel. Contudo, o rápido desenvolvimento das tecnologias Internet registado a partir do início do século XXI colocou as bibliotecas, arquivos e organizações em geral perante uma nova metamorfose: a gestão de conteúdos armazenados em suporte digital. Também nesta etapa a BGUC esteve presente, dando resposta a vários projetos de conteúdos digitais ao longo dos últimos anos.

Em 2008, decorrente da iniciativa nacional de acesso aberto (Open Access), nasce o Repositório Científico de Acesso Aberto de Portugal (RCAAP). A Universidade de Coimbra aderiu a esta iniciativa e implementa um repositório digital da produção científica designado por Estudo Geral, cujo objetivo consiste em divulgar conteúdos digitais de natureza científica de autores ligados à Universidade.

Em 2010, em resultado da integração de várias bibliotecas digitais da UC, vários tipos de fundos (livro antigo, filmes, fotografias, correspondência, etc.) são agregados num novo repositório, designado por Alma Mater.

Mais recentemente, em 2012, a Imprensa da UC manifestou interesse para disponibilizar na web as suas edições, o que deu origem à UC Digitalis, um repositório de agregação suportado pelo SIBUC, que disponibiliza atualmente toda a publicação digital da UC, designadamente a produção científica e o arquivo de livros antigos.

Neste contexto, é fácil compreender como, num curto intervalo de tempo e em resultado nos novos serviços que prestam à comunidade, a BGUC e o SIBUC se tenham tornado em importantes utilizadores de recursos de TIC, com importantes requisitos de processamento, armazenamento e disponibilidade, que the são fornecidos pelos serviços de informática da UC. Para além das infraestruturas necessárias à exploração dos serviços, as bibliotecas da UC e os seus técnicos são hoje confrontados com a imperiosa necessidade de adaptação a uma nova realidade, extremamente exigente em competências na área das TIC. A formação de 
recursos humanos na área de TIC constitui, por isso, um dos principais desafios que se colocam às bibliotecas no momento presente.

É neste enquadramento que se tem desenvolvido uma importante colaboração e troca de experiências na gestão de conteúdos digitais entre o SIBUC e os serviços de informática da UC. Tenho a expectativa de que o futuro próximo proporcionará um aprofundamento desta aproximação, determinando um alinhamento de terminologias e a adoção de boas práticas de gestão de conteúdos físicos e digitais.

Para concluir quero agradecer o convite que me foi formulado pelo Diretor da Biblioteca Geral da Universidade de Coimbra, Prof. Doutor José Augusto Bernardes, assim como à Coordenadora do SIBUC, Dra. Ana Miguéis, e à minha colega Eng. ${ }^{a}$ Ana Luísa Silva, não só pela sua contribuição para a construção desta breve memória de metamorfoses, mas também pela permanente disponibilidade e interesse para colaborar nos projetos de gestão de conteúdos digitais que temos partilhado. 
José Augusto Cardoso Bernardes é Professor da Faculdade de Letras da Universidade de Coimbra e Diretor da Biblioteca Geral da Universidade

Ana Maria Eva Miguéis é coordenadora do Serviço Integrado das Bibliotecas da Universidade de Coimbra

Carla Ferreira é bibliotecária nos Serviços de Biblioteca e Documentação da Faculdade de Letras da Universidade de Coimbra. 


\section{Série Documentos}

Imprensa da Universidade de Coimbra

Coimbra University Press

2015

C •

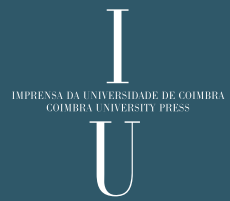

